\title{
Exosomes: mediators of bone diseases, protection, and therapeutics potential
}

\author{
Jyotirmaya Behera ${ }^{1}$ and Neetu Tyagi ${ }^{1}$ \\ ${ }^{1}$ Department of Physiology, University of Louisville School of Medicine, Louisville, KY 40202, USA \\ Correspondence to: Neetu Tyagi, email: n0tyag01@lovisville.edu \\ Keywords: osteogenesis; angiogenesis; osteoclastgenesis; osteoporosis
}

Received: November 15, $2017 \quad$ Accepted: February 06, $2018 \quad$ Published: June 23, 2018

Copyright: Behera et al. This is an open-access article distributed under the terms of the Creative Commons Attribution License 3.0 (CC BY 3.0), which permits unrestricted use, distribution, and reproduction in any medium, provided the original author and source are credited.

\section{ABSTRACT}

Bone remodeling is a continuous lifelong process in the repair of micro-damage to bone architecture and replacement of aging tissue in bone. A failure to such process leads to pathological destructive bone diseases such as osteoporosis, rheumatoid arthritis, and osteoarthritis. However, this active process is regulated by; osteoclasts, which are involved in the bone resorption process; osteoblasts, with involvement in the bone formation process and bone-derived endothelial cells, which promote angiogenesis. In the bone micro-environment, these cellular interactions are mediated by a complex interplay between cell types via direct interaction of cell secreted growth factors, such as cytokines. Recently, the discovery of exosomes ( 40-100 $\mathrm{nm}$ in size), has attracted more attention in the field of the bone remodeling process. Exosomes and microvesicles are derived from different types of bone cells such as mesenchymal stem cells, osteoblasts, osteoclasts and their precursors. They are also recognized to play pivotal roles in bone remodeling processes including osteogenesis, osteoclastogenesis, and angiogenesis. In this review, we especially emphasize the origin and biogenesis of exosomes and bone cell derived exosomes in the regulatory process of bone remodeling. Moreover, this review article also focuses on exosomal secreted proteins and microRNAs and their involvement in the regulation of bone remodeling.

\section{INTRODUCTION}

Age-related bone diseases such as osteoporosis, rheumatoid arthritis, and osteoarthritis are becoming the most universal and complex skeletal disorders worldwide [1-3]. They are characterized by disequilibrium between bone formation and bone loss upon aging and the inflammatory condition [3]. This imbalance of bone remodeling causes microarchitecture deterioration, bone fragility, and porosity as well as an increased risk of fracture $[4,5]$. Thereby, the bone healing process is remarkably delayed, as evident from other studies in osteoporotic women and osteoporotic laboratory animals $[6,7]$. Mechanistically, these skeletal defects are caused by a failure in the bone remodeling process through an imbalance in osteoclastic bone resorption and osteoblastic bone formation [1,8]. Bone remodeling is a lifelong process, where mature bone tissue is replaced from the skeleton (by osteoclasts), called bone resorption and new bone tissue is then formed called ossification or new bone formation. These processes also control the reshaping or restoration of bone mass following injuries such as, fractures and skeletal inflammation but also micro-damage, which occurs during regular activity. This involves multiple and complex cellular and molecular events [9]. However, intercellular communication or paracrine signaling among these cell types are crucial for the establishment and maintenance of bone remodeling [10-12]. As osteoclasts play a pivotal role in pathological bone resorption; receptor activator of nuclear factor- $\mathrm{\kappa B}$ ligand (RANKL) and macrophage colony-stimulating factor (M-CSF) are the key cytokines that induce osteoclastogenesis. Several master transcription factors, co-regulators, and morphogens play a pivotal role in regulating osteoblastogenesis. Several studies showed that factors such as Runx2, Osterix, Sox9, morphogens, 
TGF $\beta / B M P$ and FGFs are responsible for the terminal differentiation of osteoblast to bone mass phenotype $[13,14]$. The tight co-regulation of bone resorption and bone formation is mediated by several secreted coupling factors linking these two cellular processes together. Semaphorin 4D (Sema4D) also known as CD100, expressed by osteoclasts, acts as a negative regulator of bone formation. Consistent with an inhibitory role for Sema4D on osteoblast-lineage cells, Sema4D inhibits bone mineralization in vitro $[14,15]$. Other soluble factors such as sphingosine-1-phosphate, ephrins, and semaphorinsEphrinB2 are shown to play an essential role in cellular communication between osteoclast and osteoblast in the bone micro-environment.

Recent reports suggest that the cascade of the bone remodeling event is being regulated by critical factors that are packaged in lipid bilayered membrane vesicles called exosomes [16, 17]. Exosomes are small vesicles secreted by several cell types [18-21] and are suggested to play as essential mediators of intercellular communication [22-25]. At the present time, attention has been paid to exosomes in different pathophysiological settings. Growing evidence suggests that balanced bidirectional signaling between osteoclasts and osteoblasts mediated by exosometransplantation overcomes bone loss due to pathological destructive bone diseases [17].

In bone milieu, exosomes regulate multiple cellular processes including bone cell differentiation and bone architecture maintenance via a paracrine manner [15]. Various studies have reported that bone cells [15, 26-28] release exosomes in the bone microenvironment, which facilitates a diverse cascade of intracellular or intercellular signaling mechanisms either by targeting same cells or neighbouring cells or reaching distant organs through circulation. Exosomes are small vesicles of endocrine origin, ranging between $40-100 \mathrm{~nm}$ in diameter and are released from multivesicular bodies with potential pro-osteogenesis capabilities [16, 17]. Thus, they act through a novel way to stimulate bone formation from different pathophysiological settings. Exosomes are produced from all mammalian cell types, carrying various functional bio-molecules including proteins, mRNAs, microRNAs and lipids and also play a crucial role in intercellular communications. Importantly, exosomes do not express cell surface major histocompatibility complex (MHC-I and MHCII) proteins, and thereby overcome all the disadvantages over cell transplantation and therapy [25]. Exosomes can efficiently stimulate bone formation in vivo and in vitro [17]. In this review article, we highlight the role of bone-derived exosomes in the context of bone remodeling events by a coordinated balance of osteogenesis and osteoclastogenesis. Our review article also focuses on the diverse character of the exosome in bone marrow angiogenesis, as well as the intriguing therapeutic application of exosomes in different pathological destructive bone diseases.

\section{EXOSOME BIOGENESIS AND ITS COMPONENTS}

It is well established that the content of exosomes varies from a diverse range of proteins, lipids, and nucleic acids. Understanding the intricacies of biogenesis and exosome trafficking and how crucial they are for intercellular communications and biological functions is the hot topic of current research. According to the study of Denzer et al. (2000), biogenesis of exosomes is initiated by inward invaginations of clathrin-coated microdomains on the cell membrane [45]. Following invagination, the invaginated vacuoles are converted into early endosomes (EE) that carry ubiquitinated cargos with the help of endosomal sorting complex required for transport (ESCRT). Then EEs, upon secondary invagination, form intraluminal vesicles (ILVs), which accumulate and mature inside the endosome that is now called large multivesicular bodies (MVBs) [30, 45, 46]. The mature MVBs now have two fates: either they can be processed to lysosomes for degradation or be fused with the plasma membrane (exocytic MVBs) for the release of ILVs into the extracellular space, [31] where they are then defined as exosomes (Figure 1).

Multiple studies have shown that the contents within exosomes are used as positive 'markers' for detection of exosomes from different origins. These proteins are membrane transport and fusion proteins (GTPases, flotillin, annexins), heat shock proteins (heat shock cognate (Hsc70) and (Hsp 90), tetraspanins (CD9, CD63, CD81 and CD82), proteins involved in MVB biogenesis (Alix and TSG101), lipid-related proteins and phospholipases [46, 47, 48]. However, the most widely used markers include TSG101, Rab5b, Alix and flotillin which are detected by Western protein expression and ELISA to confirm the presence of exosomes in extracellular body fluids or culture medium. To date, 4,400 different proteins have been identified that are associated with exosomes by mass spectrometry/proteomics analysis that serve as mediators in cell-cell intercellular communications [46, 48].

Exosomes are rich in a variety of lipids depending upon their cells of origin, and different types of exosomes have altered lipid composition. There is a variety of lipid compounds that are present in exosomes including phosphatidylcholine, phosphatidylethanolamine, phosphatidylserine (PS), lysophosphatidic acid, ceramide, cholesterol, and sphingomyelin [29]. Phosphatidylserine is involved in signal transduction and fusion to the plasma membrane by docking the outer proteins through its floppase, flippase and scramblase activities [49]. Lipids such as sphingomyelin and $\mathrm{N}$-acetylneuraminic-galactosyl glucosylceramide (GM3) contribute different biophysical 
properties to exosomes and determine their rigidity and delivery efficiency [50]. Exosomes also contain nucleic acids in the form of miRNA, mRNA, and other noncoding RNAs apart from proteins and lipids [46, 51]. It is also reported that the RNA cargo of exosomes is different from that of the parent cell [46, 52]. However, cancer cells contain the same miRNA content as their parent cells which can be used as biomarkers $[46,50$, 53]. The mRNAs enriched exosomes can be translated and cause mediation of biological functions in the recipient cells, while the miRNA and ncRNAs may activate transcriptional regulation of gene expression. The work of Koppers-Lalic et al. 2013, described that the functional RNAs present in exosomes are critical

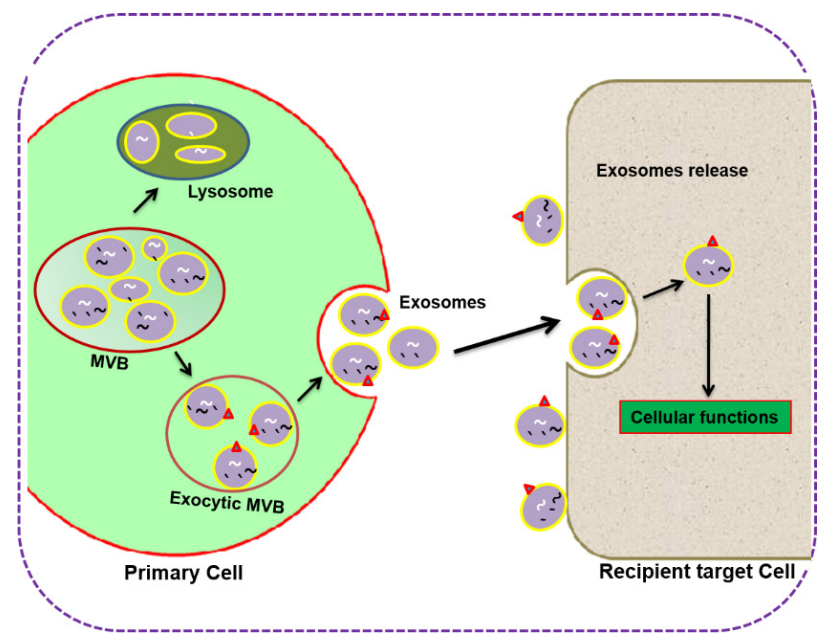

Figure 1: Biogenesis, secretion, and uptake of primary cell-derived exosomes in the target cells. Exosomes are initiated by inward invaginations of clathrin-coated microdomains on the plasma membrane and are converted into early endosomes (EE), carrying ubiquitinated cargos, facilitated by endosomal sorting complex required for transport (ESCRT). Then EEs, upon secondary invagination and maturation, convert into intraluminal vesicles (ILVs), which accumulate inside the endosomes called large multivesicular bodies (MVBs). The matured MVB can either be processed to lysosomes for degradation or fused with the plasma membrane (exocytic MVBs) for the release of ILVs into the extracellular space where it is called an exosome. Exosome secretion can be accelerated by various chemical, mechanical and environmental stimuli such as irradiation, low oxygen, and low PH. The exosomes secreted from primary cells will display various membrane components as their cells of origin. Following the release of exosomes, they may dock over the plasma membrane of recipient target cells. Furthermore, membrane-bound vesicles may either fuse with the plasma membrane directly or be endocytosed in the target cells. Upon endocytosis, exosomes may fuse with the delimiting membrane of an endocytic compartment and release its cargo contents, regulate the target cell gene expression, and finally cause cell commitment, differentiation, and activity. in the regulation of cell commitment, differentiation and activity [54]. In general, exosomes are generated from a wide range of cells and contain essential bio-molecules from their parent cells. Thus, exosomes serve as a shuttling transporter from their parent cells to target cells and mediate intercellular communication between cells. Observing the contents and considering major candidates can give credential to the bone remodeling potential of exosomes in bone disease. The main characteristics of extracellular vesicles are summarized in Table 1.

\section{ISOLATION AND PURIFICATION OF EXOSOMES}

In the last decade, impressive research innovation has been made to isolate exosomes from biological tissues or fluids. To study the potential function of exosomes, the exosomes are specially isolated from cellular components. Various techniques are employed for isolation of exosomes such as differential ultracentrifugation, size-based isolation techniques (ultrafiltration), zonal rate centrifugation, immunoaffinity capture-based techniques, exosomal precipitation, and microfluidics-based isolation techniques, etc. [55, 56]. The isolated exosomes are composed of $40-150 \mathrm{~nm}$ vesicles characterized by electron microscopy, and both immunoblotting and flow cytometry (FACS) analysis based on exosome markers expression (such as Alix, TSG101, HSP70, etc.). The proteomic profiling approach is used to characterize the protein composition of exosomes present in it, and label-free spectral counting, to evaluate the effectiveness of each method in exosome isolation [57]. However, the majority of studies use a differential ultracentrifugation technique as the gold standard of exosomes isolation. By the use of specific markers like CD13, CD29, CD44, CD73, and CD105, exosomes were isolated from mesenchymal stem cells (MSC) [22, 58]. Until now, about 1069 proteins were identified in osteoblast (MC3T3 cell line) derived exosomes from the MSC origin through the expression analysis of exosomes marker flotillin 2 [59]. A total of 786 proteins are present in the ExoCarta database. A manually created database on exosomal proteins, RNA and lipids is available at ExoCarta (http://www. exocarta.org), which catalogs information from both published and unpublished exosomal studies. Currently, ExoCarta database (Version 3.1) contains information on 11,261 protein entries, 2375 mRNA entries and 764 miRNA entries that were obtained from 134 exosomal studies [60]. Exosomes from mature osteoclasts and its precursors are characterized by the presence of specific expression markers such as epithelial cell adhesion molecule 34 (EpCAM 34), tumor susceptibility gene (TSG) 101 and CD63 [61]. 
Table 1: Types of extracellular vesicles and their characteristics.

\begin{tabular}{|c|c|c|c|}
\hline Characteristics & Exosomes & Microvesicles & Apoptotic bodies \\
\hline Size & $40-100 \mathrm{~nm}$ & $50-1000 \mathrm{~nm}$ & $50-4000 \mathrm{~nm}$ \\
\hline Morphology & Homogeneous cup-shaped & Heterogeneous irregular & Heterogeneous irregular \\
\hline Origin & $\begin{array}{l}\text { Endolysosomal pathway; } \\
\text { multivesicular body }\end{array}$ & $\begin{array}{l}\text { Cell surface; budding of cell } \\
\text { membrane }\end{array}$ & $\begin{array}{l}\text { Cell surface; blebbing of cell } \\
\text { membrane }\end{array}$ \\
\hline Morphology & Homogeneous cup-shaped & Heterogeneous irregular & Heterogeneous irregular \\
\hline Buoyant density & $1.12-1.22 \mathrm{~g} / \mathrm{cm} 3$ & None & $1.17-1.29 \mathrm{~g} / \mathrm{cm} 3$ \\
\hline Isolation method & $\begin{array}{l}\text { Density } \text { gradient } \\
\text { u } 1 \mathrm{t} \text { r a c e n t r i f u g a t i o } \mathrm{n} \\
(100,000-200,000 \text { g) and } \\
\text { by immunoprecipitation } \\
(\text { ExoQuick-INVITROGEN) }\end{array}$ & $\begin{array}{l}\text { ultracentrifugation }(10,000- \\
80,000 \mathrm{~g})\end{array}$ & $\begin{array}{l}\text { No proper standardized } \\
\text { protocol }\end{array}$ \\
\hline Molecular cargo & $\begin{array}{l}\text { mRNA, miRNA, nc RNAs, } \\
\text { mtDNAs }\end{array}$ & $\begin{array}{l}\text { mRNA, miRNA, nc RNAs, } \\
\text { mtDNAs }\end{array}$ & $\begin{array}{l}\text { Nuclear fractions and cellular } \\
\text { organelles }\end{array}$ \\
\hline Possible markers & $\begin{array}{l}\text { Tetraspanins (CD9, CD63, } \\
\text { CD81, CD82), Alix, } \\
\text { TSG101, HSP 70, flotilin-1 }\end{array}$ & $\begin{array}{l}\text { Integrin, } \mathrm{CD} 40 \\
\text { metalloproteinase, Selectin, } \\
\text { anexin V, flotilin-2 }\end{array}$ & $\begin{array}{l}\text { Phosphatidylserine and } \\
\text { histones }\end{array}$ \\
\hline Lipids & $\begin{array}{l}\text { Ceramide, cholesterol, } \\
\text { sphingomyelin } \\
\text { lysophosphatidic acid }\end{array}$ & Cholesterol & Phosphatidylserine \\
\hline Biogenesis functions & $\begin{array}{l}\text { Exocytosis of MVBs } \\
\text { via ESCRT complex or } \\
\text { sphingomyelinase and } \\
\text { release through Rab-GTPase } \\
\text { and SNAREs proteins }\end{array}$ & $\begin{array}{l}\text { Budding and fission of } \\
\text { plasma membrane through } \\
\text { intracellular calcium }\end{array}$ & $\begin{array}{l}\text { Membrane outward blebbing } \\
\text { mechanism }\end{array}$ \\
\hline References & {$[15,17,30-34,134]$} & {$[23,28,35-40]$} & {$[41-44]$} \\
\hline
\end{tabular}

\section{MOLECULAR UNDERSTANDING OF BONE REMODELING AND ITS PATHOPHYSIOLOGICAL CONSEQUENCE}

Bone remodeling is a complex, well-orchestrated process that occurs throughout life [62]. This complex coordinated event requires synchronized activities of multiple cell types to ensure bone remodeling (both bone formation and resorption) occurs sequentially to maintain bone mass [63]. A typical bone remodeling process happens within bone remodeling cavities and is performed by clusters of bone-resorbing osteoclasts, boneforming osteoblasts and associated blood vessel-forming endothelial cells, which are arranged within temporary anatomical structures known as basic multicellular units (BMUs). These BMUs are covered by bone lining cells that form the bone remodeling compartment (BRC). Furthermore, BMC is interconnected with osteocyte lacunae, which is embedded in the bone matrix. This process begins with the initiation phase by bone-resorbing osteoclasts under the regulation of osteoclastogenic factors including RANKL and M-CSF, followed by boneforming osteoblasts. However, this cycle is under the regulation of osteocytes and bone lining cell types [64]. Several coupling factors are also involved in osteoclastmediated bone resorption, such as insulin-like growth factors (IGFs), transforming growth factor $\beta$ (TGF- $\beta$ ), BMP, FGF and platelet-derived growth factor (PDGF) $[4,62]$. To completely remove the damaged or infected bone, osteoclasts express a large family of glycoproteins sematophorin $4 \mathrm{D}$ (Sema4D) that bind to Plexin-B1 receptors in osteoblasts and inhibits IGF-1 pathway dependent osteoblast differentiation [65]. This phenomenon suggests that osteoclasts suppress bone formation by expressing Sema4D. Likewise, bidirectional signaling of ephrinB2/ ephrinB4 promotes osteoblast differentiation and bone formation in the transition phase [66]. It has been reported that osteocytes act as orchestrators of the bone remodeling process despite osteoclasts and osteoblasts. Osteocytes release several factors such as sclerostin and DKK-1 that inhibit the osteoblast activity and stimulate local osteoclastogenesis $[67,68]$. Sclerostin is a product of SOST and which antagonizes Lrp5, a vital receptor of the Wnt/ $\beta$-catenin signaling pathway, in osteoblasts. For 
instance, bones subjected to pathological consequence, promote an increase in osteoclastogenesis via osteocyte expression, high RANKL/OPG levels and monocyte chemoattractant protein-1 (CCL2) expression [69]. Also, endothelial cells from capillary vessels are associated with the bone remodeling process by stimulating osteoblast activity within the BMUs. Therefore, vasculature located at the centre of BMUs may determine the process of bone resorption and bone formation. For the cortical remodeling, the capillary is provided through Haversian canals. However, the capillary supply for the trabecular remodeling comes from the marrow space [70]. The recent work suggests that endothelial specific Notch signaling promotes capillary outgrowth within the BMUs of the long bone. Genetic disruption of Notch signaling in endothelium in mice impaired vessel outgrowth and reduced osteogenesis and bone mass [70, 71].

The therapeutic potential of exosomes has been well documented in various organs and tissues such as the heart, lung, brain, and skin $[72,73,74,75]$. These studies have provided an inspiring foundation for exosomal research. Although the outcome of exosomal research is encouraging, the exact underlying molecular mechanism of bone remodeling remain elusive. Moreover, recent reports suggest that exosome treatment enhances bone remodeling in both in vivo and in vitro models.

\section{ROLE OF EXOSOMES IN BONE PHYSIOLOGY}

\section{Osteoclast exosomes: mediators of the bone remodeling process}

The recent work of Huynh et al., (2016) reported that osteoclast precursor-derived exosomes stimulate the differentiation ability of osteoclasts into mature phenotypes with significantly higher numbers than in the absence of exosomes. However, exosomes from osteoclast precursors promoted vitamin D dependent osteoclast formation in BM cultures, and exosomes from osteoclast-enriched cultures inhibited osteoclastogenesis [76]. The RANK level was enriched in exosomes from osteoclast cultures. Depletion of RANK during culture conditioning inhibits the exosome mediated osteoclast formation in vitamin D stimulated marrow cultures [76]. Therefore, this suggests, osteoclast-derived exosomes are paracrine regulators of osteoclastogenesis [76]. Recent research revealed that bone-derived exosomal micro RNAs (miRNAs) are involved in regulation of the bone remodeling process (Table 1). MicroRNAs (miRNAs) are small endogenous non-coding RNA molecules (containing 22 nucleotides), that are the key post-transcriptional repressors of gene expression. The exosomal derived novel miRNAs can modulate the differentiation and activities of osteoblasts and osteoclasts, by interacting with signaling molecules to control these processes. [77]. Mechanistically, the 5' ends of mature miRNAs contain the seed region (nucleotide positions $2-7$ or $2-8$ ), which has the ability to silence the transcription of mRNA by specifically binding to its target sequence (complementary bases of the 3 '-UTR). There are several miRNAs that have been characterized that act as negative regulators of bone formation. Osteoclast-derived exosomal microRNAs (miRNAs) represent a novel class of osteoclast-released coupling factors that cause inhibition of osteoblast differentiation. Increased osteoclastic miR214-3p is associated with reduced bone formation in elderly women with fractures and ovariectomized mice [78]. Serum exosomal miR-214 levels were also found to be significantly increased in osteoclast-specific miR214 transgenic mice [79]. Administration of chemically engineered oligonucleotides against miR-214-3p rescue the low bone formation phenotype in mice and in an in vitro osteoblast-osteoclast co-culture experiment $[15,78]$. The work of Sun et al., identified that miR-214 is elevated in osteoclast exosomes and inhibits osteoblast activity via targeting EphrinA2/EphA2 interaction through co-culture experiments [15]. Similarly, miR-214 targets ATF4 in osteoblasts to inhibit bone formation [78]. The work of Zhao et al., (2015) suggested that miR-214 promotes osteoclastogenesis through $\mathrm{PI} 3 \mathrm{~K} / \mathrm{Akt}$ pathways in BM macrophages [80]. These reports indicated that miR-214 containing exosomal osteoclasts mediate multifactorial effects that cause pathological destructive bone disease. Also, others have reported that exosomes secreted from monocytes (precursors to osteoclasts) stimulate osteogenic differentiation of MSCs [81, 82]. However, the molecular mechanism behind the osteoclast-mediated exosome activities that cause bone remodeling is a subject for future attention.

\section{Osteoblast exosomes: mediators of the bone remodeling process}

The work of Deng et al., (2015) demonstrated that exosomes released from osteoblasts (UAMS-32P cell lines) contain RANKL protein and activate RANK signaling in osteoclast precursors through receptor ligand (RANKL-RANK) interaction, leading to osteoclast formation [83]. Such exosomes-mediated intercellular communication between osteoblasts and osteoclasts may represent a novel mechanism of bone remodeling. Exosomes from BM stromal cells can activate the bone remodeling process by enhancing osteoblast differentiation and mineralization. Growth factors, bone morphogenetic protein 9 (BMP9) and transforming growth factor- $\beta 1$ (TGF- $\beta 1$ ) present in BM cell exosomes activate osteogenic differentiation [84]. The work of Solberg et al. (2015), described that osteoblast-derived lysosomal membrane protein 1 (LAMP1) positive exosomes carry RANK ligand, osteoprotegerin (OPG) and TRAP 
enzymes, which critically increase osteoclastogenesis [85]. Also, exosomes derived from mature osteoblasts also enhanced bone growth by up-regulating runtrelated transcription factor 2 (RUNX2) and alkaline phosphatase, as well as enhanced matrix mineralization [86]. Cue et al. 2016, suggest that exosomal miRNAs are produced by mineralizing osteoblasts and promote osteogenic differentiation (ST2 cells). Osteo-miRNAs (miR-30d-5p, miR-133b-3p miR-140-3p, miR-335$3 p$, miR-378b and miR-677-3p) are highly expressed which mediate bone remodeling events, by regulating osteoblast differentiation and function through Wnt signaling, insulin signaling, TGF-b signaling and calcium signaling [86]. Functional evidence suggests that miR-30d-5p and miR-133b-3p inhibit the runt-related transcription factor 2 (RUNX2) gene expression, thereby inhibiting osteoblast differentiation [86]. Others have shown that miR-140-3p diminishes osteoblast activity by suppressing BMP-2 expression [88]. miR-677-3p was found to increase axis inhibition protein 1 (AXIN1) and enhance MSC osteogenic differentiation [86]. miR-378 activates the glucosemediated osteogenic differentiation via the PI3K/Akt signaling pathway [89]. The prior reports also revealed that miR-335-5p increases osteoblast differentiation and mineralization via down-regulation of DKK-1 expression [90].

The work of $\mathrm{Xu}$ et al. (2014), reported for the first time the presence of miRNA in exosomes during BMSCs osteogenic differentiation [91]. They found that let-7a, miR-199b, miR-218, miR-148a, miR135b, miR-203, miR-219, miR-299-5p and miR-302b were significantly upregulated in exosomes derived from BMSCs. However, miR-221, miR-155, miR885-5p, miR-181a and miR-320c were significantly down-regulated in exosome samples [91]. Mechanistic studies revealed that microRNA, let-7, was reported to enhance bone formation by repressing adipogenesis in human MSCs through regulating HMGA2 gene expression [92]. The miR-218 and Wnt/ $\beta$-catenin signal was reported to promote human adipose tissue-derived stem cells osteogenic differentiation via a signalamplification circuit dependent manner [93]. miR-199b is also known to be involved in the control of osteoblast differentiation by Runx2 [92]. MicroRNA hsa-miR$135 \mathrm{~b}$ could increase the somatic cells differentiation towards to osteoblast lineage [93]. Down-regulation of miRNA-221 in exosomes was reported to trigger osteogenic differentiation in human unrestricted somatic stem cells [91]. Wnt5a, a classical noncanonical Wnt, was reported as a critical component of BMP2 mediated osteogenesis. MiR-885-5p expression negatively regulates BM2-induced osteoblast activity by repressing Runx2 [91]. miR-181a represses TGF- $\beta$ signaling molecules by inhibiting TßR-I/Alk5 (TGF- $\beta$ type I receptor) and accelerates osteoblast differentiation and mineralization [96]. Exosomal miRNAs are produced by osteoblasts and increase osteoclast activity via a paracrine mechanism. miR-148a was known to be upregulated in MSC exosomes, which further activates osteoclast differentiation and bone loss by targeting human V-maf musculoaponeurotic fibrosarcoma oncogene homolog B (MAFB) [97]. miR-503-3p from osteoblast-derived exosomes has been shown to inhibit RANK expression and RANKL-induced osteoclastogenesis [98]. In another study, human BMSC-derived extracellular vesicles are enriched with miR-196a which support bone formation in Sprague Dawley (SD) rats with calvarial defects [119]. Therefore, future research exploring the potential function of these exosomes-associated molecular factors and miRNAs, for example, paracrine/autocrine in communication between hBMSC/osteoblast or with other cell types in the field of bone remodeling, should bring new knowledge in this area. Collectively, the osteoblast-derived exosome and its molecular factors and miRNAs activate osteogenesis and bone remodeling by enhancing key osteoblast signaling molecules.

\section{EXOSOMES: POTENT ANGIOGENIC FACTORS THAT PROMOTE ANGIOGENESIS}

For a skeleton to sustain its bone mass growth and development, it has to obtain greater amounts of oxygen and nutrients through the formation of new blood vessels or angiogenesis. Angiogenesis refers to the formation of new capillaries or vessels from existing blood vessels mediated by an orchestra of a multistep process of cellular events $[98,100,101]$. Several studies reported that blood vessel development occurs through the active involvement of soluble growth factors [Fibroblast Growth Factor] (FGF) and Vascular Endothelial Growth Factor (VEGF) associated with endothelial cell growth and differentiation [99, 102], inhibiting factors (angiogenin) for proliferation and stimulating differentiation of endothelial cells [99, 103] or extracellular cytokines (angiostatin and endostatin) [104]. Mass spectroscopy analysis of exosomes profiling revealed that MSCs derived exosomes contain soluble growth factors such as VEGF, TGFB1, interleukin-8 (IL-8) and are rich in transcription factor (HGF), which accelerate the pro-angiogenic activity by stimulating both proliferation and migration of endothelial cells $[105,106]$. Similarly, human T-cell factor 4 (TCF4) is a key effector of Wnt signaling, a canonical pathway that exerts a central role in vessel development [107]. Therefore, intercellular transmission of exosomes containing HGF, HES1 and TCF4 factors may have both proangiogenic and prosurvival effects in organizing vascular phenotypes. Also, the work of Chen et al. (2010), reported that exosomes derived from MSCs contain miRNAs, including miR210, miR126, miR132, and miR21, which are shown to be involved in angiogenesis [106] and miR-6087 which 
induces endothelial differentiation [108, 109]. A recent research report has shown that exosomes from MSCs successfully accelerated angiogenesis in different in vivo animal models. The work of Bian et al. (2014), reported that bone marrow MSCs derived exosomes promotes angiogenesis in the ischemic heart by reducing myocardial ischemic/reperfusion injury in rat models [22]. In another study, it was also revealed that umbilical cord derived-MSC exosomes attenuated hind-limb ischemia by promoting blood flow [28]. In another study, exosomes derived from bone marrow tumor cells (myeloid leukemia cell line K562) were enriched with a large amount of miR-92a that enhanced angiogenesis under normoxic and hypoxic conditions [110]. With chronic hypoxia, exosomes secreted by multiple myeloma cells also improve angiogenesis by targeting factor-inhibiting hypoxia-inducible factor-1 via miR-135b. Sahoo et al. (2011), reported that exosomes from mobilized human CD34+ cells are enriched with miR-126 and miR-130a which enhances endothelial tube formation in vitro. Moreover, in vivo studies showed that the CD34+-exosomes stimulated angiogenesis in Matrigel plug assays [111]. Exosomes secreted by HMSCs, attenuate hindlimb ischemia by promoting endothelial activity and angiogenesis in mice [112]. The most recent work of Qi et al. (2016), reported that exosomes from MSCs derived from human induced pluripotent stem cell (hiPS) could promote bone regeneration in critical size bone defects in an ovariectomized rat model by enhancing both bone formation and angiogenesis [113]. This study reveals that exosomes from hiPSC-MSC accelerate significantly more neovascularisation by increasing vessel area and vessel number by enhanced osteoblast alkaline phosphatase (ALP) activity and bone formation markers (RUNX2 and COL1). Therefore, angiogenesis is only one of many intriguing effects of cell derived exosomes which have been associated with vascular capillary network formation for tissue or organ regeneration. This suggests that exosomes may be novel mediators to be employed in the treatment of various diseases. The detailed mechanism by which exosomes modulate angiogenesis in the bone microenvironment remains incompletely understood. Therefore, more research is warranted to explore the exosome mediated blood vessel development or angiogenesis that leads to the development of novel treatment for pathological destructive bone disease and remodeling. The overall feature of bone cellderived exosomal secreted factors and miRNAs and its involvement in the bone remodeling process is depicted in Table 2. Moreover, the exosomal role in the regulation of bone development and vascularization has been illustrated in (Figure 2).

\section{EXOSOMES: MEDIATORS OF SKELETAL MUSCLE REGENERATION}

Mesenchymal stem cell (MSC) transplantation is widely used for the treatment of various disease models due to its paracrine effect in tissue regeneration. Recently, exosomes have attracted special attention as new players in cell-to-cell communication for tissue regeneration. The work of Nakamura et al. (2015) has reported that MSCs-derived exosomes can promote skeletal muscle regeneration by enhancing myogenesis and angiogenesis in a muscle injury model [116]. A cytokine antibody array revealed that significant amounts of angiogenic factors such as VEGF and IL-6 are present in the MSCs derived exosomes that contribute to the regeneration of skeletal muscle [114]. On the other hand, among others, miR494 is contained abundantly in MSC-exosomes, and the results have shown that miR-494 participates in $\mathrm{C} 2 \mathrm{C} 12$ muscle myogenesis and endothelial migration activity. miR-24 is involved in myogenesis via modulation of transforming growth factor $\beta$, myogenin and MEF2 [115]. Furthermore, miR-181 is upregulated during muscle differentiation, which targets homeobox AII, a repressor of the differentiation process [116]. Thereby, it enhances muscle growth. Exosomes including both miRNAs and their secretion of cytokines or growth factors from MSCs may explain the mechanism of skeletal muscle regeneration during MSC transplantation and may be a new therapeutic tool.

\section{ROLE OF EXOSOMES IN BONE FRACTURE}

It has been reported that exosomes play as important mediators, which transfer genetic material (miRNA, mRNAs), proteins and lipids to target cells $[41,46]$. Some studies have defined stem cells, or their precursor's cells derived exosomes as being involved in a bone remodeling and repair mechanism $[115,118]$. The work of $\mathrm{J}$. Xu et al. (2014), reported for the first time that BMSC derived exosomes are enriched in let-7a, miR-199b, miR-218, miR-148a, miR-135b, miR-203, miR-219, miR-299-5p, and miR-302b, that are known to induce osteogenesis by regulating RNA degradation, the mRNA surveillance pathway, Wnt signalling pathway and RNA transport mechanism [91]. Similarly, Furuta et al. (2016), also supported the role of exosomal miRNA (miR-21, miR4532, miR-125b-5p and miR-338-3p) and bone repair related cytokines (MCP-1, -3, SDF-1 and angiogenic factors) in osteogenic bone formation in the CD9-/mouse model [117]. These enhanced fracture-healing phenotypes with bone remodeling events are due to the well-orchestrated process of osteogenesis and vascular angiogenesis. J. Zhang et al. (2016), proposed that exosome/tricalcium phosphate ( $\beta$-TCP) scaffold-mediated pro-osteogenesis effects on hBMSCs towards osteogenic lineage via pi3k-Akt signaling pathways [118]. They showed that naturally secreted nanocarriers-exosomes could act as biomaterials and potentially enhance bone repair and remodeling. In another study, BMSC-derived 
Table 2: Bone cell-derived exosomal secreted factors, miRNAs, and their involvement in the bone remodeling process.

\begin{tabular}{|c|c|c|c|}
\hline Source & $\begin{array}{|lr|}\text { Exosomes r containing } \\
\text { Secretary Factors/miRNAs }\end{array}$ & Biological functions & References \\
\hline Osteoclast & RANK & $\begin{array}{l}\text { Stimulate osteoclasts and } \\
\text { osteoblastic } \quad \text { differentiation } \\
\text { in bone }\end{array}$ & {$[74]$} \\
\hline Osteoclast & EphA2, B2 & Osteoblast differentiation & {$[76,66]$} \\
\hline Osteoclast & IGF, & Activate osteoblast migration & {$[77]$} \\
\hline Pre-osteoclast & PDGF & $\begin{array}{l}\text { Promotes angiogenesis } \\
\text { by specific endothelial } \\
(\mathrm{CD} 31+\mathrm{EMCN}+) \text { cell types }\end{array}$ & {$[78]$} \\
\hline Osteoclast & Cardiotropins-1 & $\begin{array}{lr}\text { Accelerates } & \text { osteoblast } \\
\text { differentiation } & \text { and } \\
\text { mineralization } & \end{array}$ & [79] \\
\hline Osteoblast & RANKL & $\begin{array}{l}\text { osteoclast formation and } \\
\text { activity }\end{array}$ & {$[83]$} \\
\hline Osteoblast & OPG & $\begin{array}{l}\text { Inhibit the osteoclast } \\
\text { differentiation through OPG- } \\
\text { RANKL interaction }\end{array}$ & {$[17,83]$} \\
\hline Osteoblast & TRAP & Increase the osteoclastgenesis & {$[17,85]$} \\
\hline Osteoblast & $\mathrm{PP} 1 \mathrm{C}$ and $\mathrm{PABP}$ & $\begin{array}{l}\text { Regulate EIF2 signaling } \\
\text { pathway in osteogenesis }\end{array}$ & {$[86,87]$} \\
\hline MSCs & Undefined factors? & $\begin{array}{l}\text { Promotes osteogenesis and } \\
\text { angiogenesis }\end{array}$ & {$[115]$} \\
\hline Osteoclast & MiRNA-214 & $\begin{array}{l}\text { inhibits the osteoblast } \\
\text { activity via targeting } \\
\text { EphrinA2/EphA2 interaction } \\
\text { and also targets ATF4 to } \\
\text { inhibit bone formation }\end{array}$ & {$[15,78]$} \\
\hline HBMSCs & miR-135b & $\begin{array}{lr}\text { Inhibits } & \text { osteoblast } \\
\text { differentiation by } & \text { targeting } \\
\text { IBSP and Osterix }\end{array}$ & {$[94,95]$} \\
\hline HBMSCs & $\operatorname{miR}-885-5 p$ & $\begin{array}{lr}\text { Inhibits } & \text { osteogenic } \\
\text { differentiation by targeting } \\
\text { RUNX2 }\end{array}$ & {$[91]$} \\
\hline HBMSCs & miR-181a & $\begin{array}{l}\text { Increases osteoblast activity } \\
\text { and mineralization through } \\
\text { TGF-BI regulation }\end{array}$ & {$[96]$} \\
\hline HBMSCs & miR-218 & $\begin{array}{lr}\text { Accelerates } & \text { osteoblast } \\
\text { differentiation } & \text { and } \\
\text { mineralization } & \text { through } \text { Wnt } \\
\text { signaling } & \end{array}$ & {$[131]$} \\
\hline HBMSCs & miR-196a & $\begin{array}{lr}\text { Increases } & \text { osteoblast } \\
\text { differentiation } & \text { and } \\
\text { mineralization by } & \text { targeting } \\
\text { HOXC8 } & \end{array}$ & {$[119,133]$} \\
\hline
\end{tabular}




\begin{tabular}{|c|c|c|c|}
\hline HBMSCs & miR-148a & $\begin{array}{|lr|}\text { Increases the } & \text { osteoclast } \\
\text { differentiation } & \text { through } \\
\text { by targeting } & \text { V-maf } \\
\text { musculoapone urotic } \\
\text { fibrosarcoma } & \text { oncogene } \\
\text { homolog B } & \end{array}$ & {$[92,97]$} \\
\hline HBMSCs & let-7 & $\begin{array}{l}\text { Increase osteogenesis and } \\
\text { bone formation by HMGA2 }\end{array}$ & {$[92]$} \\
\hline Osteoblast & miR-503-3p & 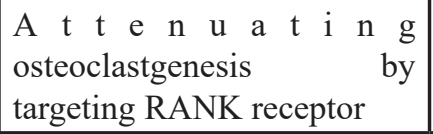 & {$[98]$} \\
\hline Osteoblast & miR-133b-3p & \begin{tabular}{|lllllll} 
A t $\quad$ e & u & a & t & i & n \\
osteoblastgenesis & & & by \\
targeting RUNX2 & & & &
\end{tabular} & {$[132]$} \\
\hline Osteoblast & miR-30d-3p & \begin{tabular}{|llll} 
A $\mathrm{t} \mathrm{t}$ e $\mathrm{n} \mathrm{u}$ a & $\mathrm{t}$ & $\mathrm{i}$ & $\mathrm{n}$ \\
osteoblastgenesis & & by \\
targeting RUNX2 & & & \\
\end{tabular} & {$[87]$} \\
\hline Osteoblast & miR-677-3p & $\begin{array}{l}\text { Promotes MSC osteogenic } \\
\text { differentiation via targeting } \\
\text { AXIN1 }\end{array}$ & {$[86]$} \\
\hline
\end{tabular}

exosomes were found to be enriched in osteogenic-related miRNAs, miR-196a, miR-27a and miR-206, which were highly upregulated. They further confirmed these findings with in vitro functional studies $[119,120]$.

\section{ROLE OF EXOSOMES AS CLINICAL THERAPEUTICS IN BONE DISEASE}

Due to several cellular and molecular traits like selfrenewal, vast differentiation and a variety of ECM protein secretion, MSCs have been proposed to be an important candidate for tissue repair, especially for mass bone restoration. However, several therapeutic findings of MSCs or its precursors-derived exosomes have been reported in the field of orthopaedics [121, 122, 123]. However, debilitating bone disease such as osteoporosis, rheumatoid arthritis (RA) and osteoarthritis brought significant attention in clinics to recover patients from inflammation, T-cell activation, and imbalanced bone remodeling, which lead to pain and deterioration of bone mass and joints. However, there is no direct study on the role of stem cell-derived exosomes that mitigate the imbalance in the remodeling process in the aforementioned destructive bone diseases. The work of Zhang et al. (2015), reported that exosomes released from human iPS-derived MSCs improve cutaneous wound healing in a murine model by enhancing collagen synthesis and angiogenesis [124]. In another study, ESC-derived exosomes improved cardiac function by strengthening myocardial neovascularization via a miRNA-290-295 dependent manner following myocardial infarction [125]. The work of Nakamura et al. (2015), also reported the emerging role of MSC-derived exosomes in being able to accelerate skeletal muscle regeneration via miRNA-494 in a skeletal muscle injury model [116]. Bone vascularization is essential for many physiological processes, such as bone development and growth, and bone remodeling. The work of Qi et al. (2016), also reported that MSCs derived exosomes from hiPS can promote bone formation and vascularization in critical size bone defects in an ovariectomized rat model

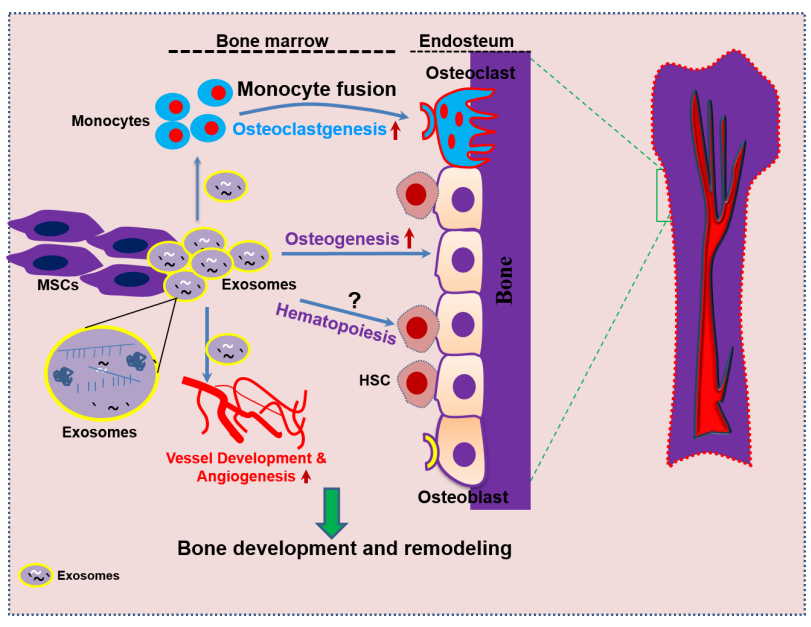

Figure 2: Bone marrow-MSC derived exosomes enhance bone regeneration by orchestrating a coordinated regulation of osteogenesis, angiogenesis, and osteoclastogenesis. In the bone microenvironment, bone marrow-MSCs actively secrete exosomes, which are taken up by the surrounding cells including osteoblasts, osteoclasts, and endothelial cells. These activities result in a complex interplay of bone homeostasis by accelerating osteogenesis, osteoclastogenesis, and angiogenesis of which may promote vascularized bone development and regeneration. 
[115]. Interestingly, in a murine model of delayed-type hypersensitivity and collagen-induced arthritis, EVs containing adenovirus expressing viral IL-10 or bone marrow-derived DCs treated with recombinant murine IL-10 suppressed the inflammatory and autoimmune responses when injected particularly [126]. This may represent a novel, cell-free therapy for the treatment and has major applications in the field of osteobiology and orthopaedics. However, if such type of MSCs or BM-derived exosomes could be isolated on a large scale in clinical practice that could be a major therapeutic intervention in debilitating bone diseases, including osteoporosis, rheumatoid arthritis, and osteoarthritis.

\section{THERAPEUTIC ADVANTAGE OF EXOSOMES TREATMENT AND FUTURE DIRECTIONS}

Much of the excitement surrounding extracellular vesicles/exosomes research is due to its high clinical relevance. This is due, in particular, because bone exosomes can be easily isolated through minimally invasive procedures, such as from the bone marrow or MSCs of healthy donor patients, as they have great potential in destructive bone disease diagnosis. Also, exosome treatments have several advantages due to fewer safety concerns over cell-based treatments and reduce toxicity and immunogenicity problems [115, 127]. Also, exosomes do not express cell surface MHCI or MHCII proteins and thereby prevent immunogenicity better than cell-based transplantation therapy [128] which can effectively stimulate bone remodeling in vivo and in vitro [124]. MSC-derived exosomes also maintain their privileged immune properties of their origins, and this may significantly help researchers to develop novel immunotherapies [129]. Additionally, in comparison with living cells, nonviable exosomes are more stable, have no risk of aneuploidy and a low possibility of immune rejection following in vivo administration [75]. Multiple prior studies have reported the use of MSCs and miRNAs in bone repair and remodeling [121-123, 130]. The above findings suggest that stem cell-derived exosomes will one day be able to provide the best possible clinical medicine in the field of bone repair and remodeling therapy. Since MSCs derived exosomes accomplish such recovery tasks, further research will be needed to identify a novel exosome; thereby efficiently recovering the bone remodeling phenomena in the in vivo condition. Therefore, they can provide an alternative therapy for bone and other diseases.

\section{CONCLUSIONS}

In conclusion, our review article collectively focused on the recent approaches towards the therapeutic application of exosomes in the bone remodeling process, which regulates osteoclastogenesis, osteoblastogenesis, and angiogenesis. However, the molecular mechanism behind the exosomes mediated signaling cascade in bone remodeling and development remains elusive. Biomedical application of exosomal based medication will bring a new challenge in clinical practice. To improve such clinical conditions, at the very least, novel reliable methods must be developed for easy purification of exosomes in large-scale production, and for co-expression of different molecules (proteins, mRNA, and miRNA) that affect physiological function and its administration route needs to achieve targeted delivery and recovery of pathological outcomes to be determined. Considering the enormous importance of exosome-based clinical therapy, it could be a new and safe approach for debilitating bone diseases more so than other gene and cell-based therapies.

\section{Abbreviations}

ESCRT: Endosomal sorting complexes required for transport; SNARE: Soluble NSF Attachment Protein Receptor, EMCN: Endomucin; IBSP: Integrin binding sialoprotein

\section{CONFLICTS OF INTEREST}

The authors declare no conflict of interest.

\section{FUNDING}

This work was supported by National Institutes of Health grants: AR-067667 and HL-107640.

\section{REFERENCES}

1. Sućur A, Katavić V, Kelava T, Jajić Z, Kovačić N, Grčević D. Induction of osteoclast progenitors in inflammatory conditions: key to bone destruction in arthritis. Int Orthop. 2014; 38:1893-903.

2. Manolagas SC. Steroids and osteoporosis: the quest for mechanisms. J Clin Invest. 2013; 123:1919-21.

3. Withrow J, Murphy C, Liu Y, Hunter M, Fulzele S, Hamrick MW. Extracellular vesicles in the pathogenesis of rheumatoid arthritis and osteoarthritis. Arthritis Res Ther. 2016; 18:286.

4. Henriksen K, Karsdal MA, Martin TJ. Osteoclast-derived coupling factors in bone remodeling. Calcif Tissue Int. 2014; 94:88-97.

5. Rachner TD, Khosla S, Hofbauer LC. Osteoporosis: now and the future. Lancet. 2011; 377:1276-87.

6. Hao YJ, Zhang G, Wang YS, Qin L, Hung WY, Leung K, Pei FX. Changes of microstructure and mineralized tissue in the middle and late phase of osteoporotic fracture healing 
in rats. Bone. 2007; 41:631-38.

7. McCann RM, Colleary G, Geddis C, Clarke SA, Jordan GR, Dickson GR, Marsh D. Effect of osteoporosis on bone mineral density and fracture repair in a rat femoral fracture model. J Orthop Res. 2008; 26:384-93.

8. Sims NA, Martin TJ. Coupling the activities of bone formation and resorption: a multitude of signals within the basic multicellular unit. Bonekey Rep. 2014; 3:481.

9. Raggatt LJ, Partridge NC. Cellular and molecular mechanisms of bone remodeling. J Biol Chem. 2010; 285:25103-08.

10. Miyazaki T, Tanaka S, Sanjay A, Baron R. The role of c-Src kinase in the regulation of osteoclast function. Mod Rheumatol. 2006; 16:68-74.

11. Edwards CM, Mundy GR. Eph receptors and ephrin signaling pathways: a role in bone homeostasis. Int J Med Sci. 2008; 5:263-72.

12. Del Fattore A, Teti A, Rucci N. Osteoclast receptors and signaling. Arch Biochem Biophys. 2008; 473:147-60.

13. Javed A, Chen H, Ghori FY. Genetic and transcriptional control of bone formation. Oral Maxillofac Surg Clin North Am. 2010; 22:283-93.

14. Sims NA, Walsh NC. Intercellular cross-talk among bone cells: new factors and pathways. Curr Osteoporos Rep. 2012; 10:109-17.

15. Sun W, Zhao C, Li Y, Wang L, Nie G, Peng J, Wang A, Zhang $\mathrm{P}$, Tian $\mathrm{W}$, Li Q, Song J, Wang $\mathrm{C}, \mathrm{Xu} \mathrm{X}$, et al. Osteoclast-derived microRNA-containing exosomes selectively inhibit osteoblast activity. Cell Discov. 2016; 2:16015.

16. van der Eerden BC. MicroRNAs in the skeleton: cellrestricted or potent intercellular communicators? Arch Biochem Biophys. 2014; 561:46-55.

17. Xie Y, Chen Y, Zhang L, Ge W, Tang P. The roles of bonederived exosomes and exosomal microRNAs in regulating bone remodelling. J Cell Mol Med. 2017; 21:1033-41.

18. Théry C, Regnault A, Garin J, Wolfers J, Zitvogel L, Ricciardi-Castagnoli P, Raposo G, Amigorena S. Molecular characterization of dendritic cell-derived exosomes. Selective accumulation of the heat shock protein hsc73. J Cell Biol. 1999; 147:599-610.

19. Blanchard N, Lankar D, Faure F, Regnault A, Dumont C, Raposo G, Hivroz C. TCR activation of human T cells induces the production of exosomes bearing the TCR/CD3/ zeta complex. J Immunol. 2002; 168:3235-41.

20. Théry C, Ostrowski M, Segura E. Membrane vesicles as conveyors of immune responses. Nat Rev Immunol. 2009; 9:581-93.

21. Ohno S, Takanashi M, Sudo K, Ueda S, Ishikawa A, Matsuyama N, Fujita K, Mizutani T, Ohgi T, Ochiya T, Gotoh N, Kuroda M. Systemically injected exosomes targeted to EGFR deliver antitumor microRNA to breast cancer cells. Mol Ther. 2013; 21:185-91.

22. Bian S, Zhang L, Duan L, Wang X, Min Y, Yu H.
Extracellular vesicles derived from human bone marrow mesenchymal stem cells promote angiogenesis in a rat myocardial infarction model. J Mol Med (Berl). 2014; 92:387-97.

23. Valenti R, Huber V, Iero M, Filipazzi P, Parmiani G, Rivoltini L. Tumor-released microvesicles as vehicles of immunosuppression. Cancer Res. 2007; 67:2912-15.

24. Beninson LA, Fleshner M. Exosomes: an emerging factor in stress-induced immunomodulation. Semin Immunol. 2014; 26:394-401.

25. Holliday LS, McHugh KP, Zuo J, Aguirre JI, Neubert JK, Rody WJ Jr. Exosomes: novel regulators of bone remodelling and potential therapeutic agents for orthodontics. Orthod Craniofac Res. 2017 (Suppl 1); 20:95-99.

26. Deng L, Wang Y, Peng Y, Wu Y, Ding Y, Jiang Y, Shen Z, Fu Q. Osteoblast-derived microvesicles: A novel mechanism for communication between osteoblasts and osteoclasts. Bone. 2015; 79:37-42.

27. Xu S, Wang Z. Bone marrow mesenchymal stem cellderived exosomes enhance osteoclastogenesis during alveolar bone deterioration in rats. RSC Adv. 2017; 7: 21153-21163.

28. Zhang HC, Liu XB, Huang S, Bi XY, Wang HX, Xie LX, Wang YQ, Cao XF, Lv J, Xiao FJ, Yang Y, Guo $Z K$. Microvesicles derived from human umbilical cord mesenchymal stem cells stimulated by hypoxia promote angiogenesis both in vitro and in vivo. Stem Cells Dev. 2012; 21:3289-97.

29. Théry C, Zitvogel L, Amigorena S. Exosomes: composition, biogenesis and function. Nat Rev Immunol. 2002; 2: 569-579.

30. Trajkovic K, Hsu C, Chiantia S, Rajendran L, Wenzel D, Wieland F, Schwille P, Brügger B, Simons M. Ceramide triggers budding of exosome vesicles into multivesicular endosomes. Science. 2008; 319:1244-47.

31. Mathivanan S, Ji H, Simpson RJ. Exosomes: extracellular organelles important in intercellular communication. J Proteomics. 2010; 73:1907-20.

32. Subra C, Laulagnier K, Perret B, Record M. Exosome lipidomics unravels lipid sorting at the level of multivesicular bodies. Biochimie. 2007; 89:205-12.

33. Vidal M, Sainte-Marie J, Philippot JR, Bienvenue A. Asymmetric distribution of phospholipids in the membrane of vesicles released during in vitro maturation of guinea pig reticulocytes: evidence precluding a role for "aminophospholipid translocase". J Cell Physiol. 1989; 140:455-62.

34. Heijnen HF, Schiel AE, Fijnheer R, Geuze HJ, Sixma JJ. Activated platelets release two types of membrane vesicles: microvesicles by surface shedding and exosomes derived from exocytosis of multivesicular bodies and alphagranules. Blood. 1999; 94:3791-99.

35. Herrera MB, Fonsato V, Gatti S, Deregibus MC, Sordi A, Cantarella D, Calogero R, Bussolati B, Tetta C, Camussi 
G. Human liver stem cell-derived microvesicles accelerate hepatic regeneration in hepatectomized rats. J Cell Mol Med. 2010; 14:1605-18.

36. Deregibus MC, Cantaluppi V, Calogero R, Lo Iacono M, Tetta C, Biancone L, Bruno S, Bussolati B, Camussi G. Endothelial progenitor cell derived microvesicles activate an angiogenic program in endothelial cells by a horizontal transfer of mRNA. Blood. 2007; 110:2440-48.

37. Bucki R, Bachelot-Loza C, Zachowski A, Giraud F, Sulpice JC. Calcium induces phospholipid redistribution and microvesicle release in human erythrocyte membranes by independent pathways. Biochemistry. 1998; 37:15383-91.

38. Scott S, Pendlebury SA, Green C. Lipid organization in erythrocyte membrane microvesicles. Biochem J. 1984; 224:285-90.

39. Zwaal RF, Comfurius P, Bevers EM. Platelet procoagulant activity and microvesicle formation. Its putative role in hemostasis and thrombosis. Biochim Biophys Acta. 1992; 1180:1-8.

40. Collino F, Deregibus MC, Bruno S, Sterpone L, Aghemo G, Viltono L, Tetta C, Camussi G. Microvesicles derived from adult human bone marrow and tissue specific mesenchymal stem cells shuttle selected pattern of miRNAs. PLoS One. 2010; 5:e11803.

41. Hashimoto S, Ochs RL, Rosen F, Quach J, McCabe G, Solan J, Seegmiller JE, Terkeltaub R, Lotz M. Chondrocytederived apoptotic bodies and calcification of articular cartilage. Proc Natl Acad Sci USA. 1998; 95:3094-99.

42. Atkin-Smith GK, Paone S, Zanker DJ, Duan M, Phan TK, Chen W, Hulett MD, Poon IK. Isolation of cell type-specific apoptotic bodies by fluorescence-activated cell sorting. Sci Rep. 2017; 7:39846.

43. Kirsch T, Wang W, Pfander D. Functional differences between growth plate apoptotic bodies and matrix vesicles. J Bone Miner Res. 2003; 18:1872-81.

44. Stuart MC, Damoiseaux JG, Frederik PM, Arends JW, Reutelingsperger CP. Surface exposure of phosphatidylserine during apoptosis of rat thymocytes precedes nuclear changes. Eur J Cell Biol. 1998; 76:77-83.

45. Denzer K, Kleijmeer MJ, Heijnen HF, Stoorvogel W, Geuze HJ. Exosome: from internal vesicle of the multivesicular body to intercellular signaling device. J Cell Sci. 2000; 113:3365-74.

46. Kalani A, Tyagi A, Tyagi N. Exosomes: mediators of neurodegeneration, neuroprotection and therapeutics. Mol Neurobiol. 2014; 49:590-600.

47. Vlassov AV, Magdaleno S, Setterquist R, Conrad R. Exosomes: current knowledge of their composition, biological functions, and diagnostic and therapeutic potentials. Biochim Biophys Acta. 2012; 1820:940-48.

48. Mathivanan S, Simpson RJ. ExoCarta: A compendium of exosomal proteins and RNA. Proteomics. 2009; 9:49975000 .

49. Zomer A, Vendrig T, Hopmans ES, van Eijndhoven M,
Middeldorp JM, Pegtel DM. Exosomes: fit to deliver small RNA. Commun Integr Biol. 2010; 3:447-50.

50. Rabinowits G, Gerçel-Taylor C, Day JM, Taylor DD, Kloecker GH. Exosomal microRNA: a diagnostic marker for lung cancer. Clin Lung Cancer. 2009; 10:42-46.

51. Valadi H, Ekström K, Bossios A, Sjöstrand M, Lee JJ, Lötvall JO. Exosome-mediated transfer of mRNAs and microRNAs is a novel mechanism of genetic exchange between cells. Nat Cell Biol. 2007; 9:654-59.

52. Mittelbrunn M, Gutiérrez-Vázquez C, Villarroya-Beltri C, González S, Sánchez-Cabo F, González MÁ, Bernad A, Sánchez-Madrid F. Unidirectional transfer of microRNAloaded exosomes from $\mathrm{T}$ cells to antigenpresenting cells. Nat Commun. 2011; 2:282.

53. Taylor DD, Gercel-Taylor C. MicroRNA signatures of tumor-derived exosomes as diagnostic biomarkers of ovarian cancer. Gynecol Oncol. 2008; 110:13-21.

54. Koppers-Lalic D, Hogenboom MM, Middeldorp JM, Pegtel DM. Virus-modified exosomes for targeted RNA delivery; a new approach in nanomedicine. Adv Drug Deliv Rev. 2013; 65:348-56.

55. Li P, Kaslan M, Lee SH, Yao J, Gao Z. Progress in Exosome Isolation Techniques. Theranostics. 2017; 7:789-804.

56. Simpson RJ, Jensen SS, Lim JW. Proteomic profiling of exosomes: current perspectives. Proteomics. 2008; 8:408399.

57. Greening DW, Xu R, Ji H, Tauro BJ, Simpson RJ. A protocol for exosome isolation and characterization: evaluation of ultracentrifugation, density-gradient separation, and immunoaffinity capture methods. Methods Mol Biol. 2015; 1295:179-209.

58. Yang X, Matsuda K, Bialek P, Jacquot S, Masuoka HC, Schinke T, Li L, Brancorsini S, Sassone-Corsi P, Townes TM, Hanauer A, Karsenty G. ATF4 is a substrate of RSK2 and an essential regulator of osteoblast biology; implication for Coffin-Lowry Syndrome. Cell. 2004; 117:387-98.

59. Ge M, Ke R, Cai T, Yang J, Mu X. Identification and proteomic analysis of osteoblast-derived exosomes. Biochem Biophys Res Commun. 2015; 467:27-32.

60. Mathivanan S, Fahner CJ, Reid GE, Simpson RJ. ExoCarta 2012: database of exosomal proteins, RNA and lipids. Nucleic Acids Res. 2012; 40:D1241-44.

61. Pols MS, Klumperman J. Trafficking and function of the tetraspanin CD63. Exp Cell Res. 2009; 315:1584-92.

62. Dimitriou R, Jones E, McGonagle D, Giannoudis PV. Bone regeneration: current concepts and future directions. BMC Med. 2011; 9: 66.

63. Rucci N. Molecular biology of bone remodelling. Clin Cases Miner Bone Metab. 2008; 5:49-56.

64. Feng X, McDonald JM. Disorders of bone remodeling. Annu Rev Pathol. 2011; 6:121-45.

65. Negishi-Koga T, Shinohara M, Komatsu N, Bito H, Kodama T, Friedel RH, Takayanagi H. Suppression of bone formation by osteoclastic expression of semaphorin 4D. 
Nat Med. 2011; 17:1473-80.

66. Zhao C, Irie N, Takada Y, Shimoda K, Miyamoto T, Nishiwaki T, Suda T, Matsuo K. Bidirectional ephrinB2EphB4 signaling controls bone homeostasis. Cell Metab. 2006; 4:111-21.

67. Robling AG, Bellido T, Turner CH. Mechanical stimulation in vivo reduces osteocyte expression of sclerostin. J Musculoskelet Neuronal Interact. 2006; 6:354.

68. Bonewald LF, Johnson ML. Osteocytes, mechanosensing and Wnt signaling. Bone. 2008; 42:606-15.

69. Moriishi T, Fukuyama R, Ito M, Miyazaki T, Maeno T, Kawai Y, Komori H, Komori T. Osteocyte network; a negative regulatory system for bone mass augmented by the induction of Rankl in osteoblasts and Sost in osteocytes at unloading. PLoS One. 2012; 7:e40143.

70. Ramasamy SK, Kusumbe AP, Wang L, Adams RH. Endothelial Notch activity promotes angiogenesis and osteogenesis in bone. Nature. 2014; 507:376-80.

71. Eriksen EF. Cellular mechanisms of bone remodeling. Rev Endocr Metab Disord. 2010; 11:219-27.

72. Yamaguchi T, Izumi Y, Nakamura Y, Yamazaki T, Shiota M, Sano S, Tanaka M, Osada-Oka M, Shimada K, Miura $\mathrm{K}$, Yoshiyama M, Iwao H. Repeated remote ischemic conditioning attenuates left ventricular remodeling via exosome-mediated intercellular communication on chronic heart failure after myocardial infarction. Int $\mathrm{J}$ Cardiol. $2015 ; 178: 239-46$.

73. Lee C, Mitsialis SA, Aslam M, Vitali SH, Vergadi E, Konstantinou G, Sdrimas K, Fernandez-Gonzalez A, Kourembanas S. Exosomes mediate the cytoprotective action of mesenchymal stromal cells on hypoxia-induced pulmonary hypertension. Circulation. 2012; 126:2601-11.

74. Alvarez-Erviti L, Seow Y, Yin H, Betts C, Lakhal S, Wood MJ. Delivery of siRNA to the mouse brain by systemic injection of targeted exosomes. Nat Biotechnol. 2011; 29:341-45.

75. Basu J, Ludlow JW. Exosomes for repair, regeneration and rejuvenation. Expert Opin Biol Ther. 2016; 16:489-506.

76. Huynh N, VonMoss L, Smith D, Rahman I, Felemban MF, Zuo J, Rody WJ Jr, McHugh KP, Holliday LS. Characterization of regulatory extracellular vesicles from osteoclasts. J Dent Res. 2016; 95:673-79.

77. Rigoutsos I, Furnari F. Gene-expression forum: decoy for microRNAs. Nature. 2010; 465:1016-17.

78. Li D, Liu J, Guo B, Liang C, Dang L, Lu C, He X, Cheung HY, Xu L, Lu C, He B, Liu B, Shaikh AB, et al. Osteoclastderived exosomal miR-214-3p inhibits osteoblastic bone formation. Nat Commun. 2016; 7:10872.

79. Wang X, Guo B, Li Q, Peng J, Yang Z, Wang A, Li D, Hou Z, Lv K, Kan G, Cao H, Wu H, Song J, et al. miR-214 targets ATF4 to inhibit bone formation. Nat Med. 2013; 19:93-100.
80. Zhao C, Sun W, Zhang P, Ling S, Li Y, Zhao D, Peng J, Wang A, Li Q, Song J, Wang C, Xu X, Xu Z, et al. miR-214 promotes osteoclastogenesis by targeting Pten/PI3k/Akt pathway. RNA Biol. 2015; 12:343-53.

81. Ekström K, Omar O, Granéli C, Wang X, Vazirisani F, Thomsen P. Monocyte exosomes stimulate the osteogenic gene expression of mesenchymal stem cells. PLoS One. 2013; 8:e75227.

82. Omar OM, Granéli C, Ekström K, Karlsson C, Johansson A, Lausmaa J, Wexell CL, Thomsen P. The stimulation of an osteogenic response by classical monocyte activation. Biomaterials. 2011; 32:8190-204.

83. Feng-Lai Yuan, Qian-yuan Wu, Zong-Ning Miao, MingHui Xu, Rui-Sheng Xu, Dong-Lin Jiang, Jun-Xing Ye, Fei-hu Chen, Ming-Dong Zhao, Hao-jue Wang, Xia Li. Osteoclast-Derived Extracellular Vesicles: Novel Regulators of Osteoclastogenesis and OsteoclastOsteoblasts Communication in Bone Remodeling. Front Physiol. 2018; 9: 628.

84. Zhao L, Jiang S, Hantash BM. Transforming growth factor beta1 induces osteogenic differentiation of murine bone marrow stromal cells. Tissue Eng Part A. 2010; 16:725-33.

85. Solberg LB, Stang E, Brorson SH, Andersson G, Reinholt FP. Tartrate-resistant acid phosphatase (TRAP) co-localizes with receptor activator of NF-KB ligand (RANKL) and osteoprotegerin (OPG) in lysosomal-associated membrane protein 1 (LAMP1)-positive vesicles in rat osteoblasts and osteocytes. Histochem Cell Biol. 2015; 143:195-207.

86. Cui Y, Luan J, Li H, Zhou X, Han J. Exosomes derived from mineralizing osteoblasts promote ST2 cell osteogenic differentiation by alteration of microRNA expression. FEBS Lett. 2016; 590:185-92.

87. Zhang Y, Xie RL, Croce CM, Stein JL, Lian JB, van Wijnen AJ, Stein GS. A program of microRNAs controls osteogenic lineage progression by targeting transcription factor Runx 2 . Proc Natl Acad Sci USA. 2011; 108:9863-68.

88. Hwang S, Park SK, Lee HY, Kim SW, Lee JS, Choi EK, You D, Kim CS, Suh N. miR-140-5p suppresses BMP2-mediated osteogenesis in undifferentiated human mesenchymal stem cells. FEBS Lett. 2014; 588: 2957-63.

89. You L, Gu W, Chen L, Pan L, Chen J, Peng Y. MiR378 overexpression attenuates high glucose-suppressed osteogenic differentiation through targeting CASP3 and activating PI3K/Akt signaling pathway. Int J Clin Exp Pathol. 2014; 7:7249-61.

90. Zhang J, Tu Q, Bonewald LF, He X, Stein G, Lian J, Chen J. Effects of miR-335-5p in modulating osteogenic differentiation by specifically downregulating Wnt antagonist DKK1. J Bone Miner Res. 2011; 26:1953-63.

91. Xu JF, Yang GH, Pan XH, Zhang SJ, Zhao C, Qiu BS, Gu HF, Hong JF, Cao L, Chen Y, Xia B, Bi Q, Wang YP. Altered microRNA expression profile in exosomes during osteogenic differentiation of human bone marrow-derived 
mesenchymal stem cells. PLoS One. 2014; 9:e114627.

92. Wei J, Li H, Wang S, Li T, Fan J, Liang X, Li J, Han Q, Zhu L, Fan L, Zhao RC. let-7 enhances osteogenesis and bone formation while repressing adipogenesis of human stromal/mesenchymal stem cells by regulating HMGA2. Stem Cells Dev. 2014; 23:1452-63.

93. Zhang WB, Zhong WJ, Wang L. A signal-amplification circuit between miR-218 and $\mathrm{Wnt} / \beta$-catenin signal promotes human adipose tissue-derived stem cells osteogenic differentiation. Bone. 2014; 58:59-66.

94. Lauvrak SU, Munthe E, Kresse SH, Stratford EW, Namløs HM, Meza-Zepeda LA, Myklebost O. Functional characterisation of osteosarcoma cell lines and identification of mRNAs and miRNAs associated with aggressive cancer phenotypes. Br J Cancer. 2013; 109:2228-36.

95. Schaap-Oziemlak AM, Raymakers RA, Bergevoet SM, Gilissen C, Jansen BJ, Adema GJ, Kögler G, le Sage C, Agami R, van der Reijden BA, Jansen JH. MicroRNA hsa-miR-135b regulates mineralization in osteogenic differentiation of human unrestricted somatic stem cells. Stem Cells Dev. 2010; 19:877-85.

96. Bhushan R, Grünhagen J, Becker J, Robinson PN, Ott CE, Knaus P. miR-181a promotes osteoblastic differentiation through repression of TGF- $\beta$ signaling molecules. Int $\mathrm{J}$ Biochem Cell Biol. 2013; 45:696-705.

97. Cheng P, Chen C, He HB, Hu R, Zhou HD, Xie H, Zhu W, Dai RC, Wu XP, Liao EY, Luo XH. miR-148a regulates osteoclastogenesis by targeting V-maf musculoaponeurotic fibrosarcoma oncogene homolog B. J Bone Miner Res. 2013; 28:1180-90.

98. Chen C, Cheng P, Xie H, Zhou HD, Wu XP, Liao EY, Luo XH. MiR-503 regulates osteoclastogenesis via targeting RANK. J Bone Miner Res. 2014; 29:338-47.

99. Merino-González C, Zuñiga FA, Escudero C, Ormazabal V, Reyes C, Nova-Lamperti E, Salomón C, Aguayo C. Mesenchymal Stem Cell-Derived Extracellular Vesicles Promote Angiogenesis: Potencial Clinical Application. Front Physiol. 2016; 7:24.

100. Adams RH, Alitalo K. Molecular regulation of angiogenesis and lymphangiogenesis. Nat Rev Mol Cell Biol. 2007; 8:464-78.

101. Bazigou E, Makinen T. Flow control in our vessels: vascular valves make sure there is no way back. Cell Mol Life Sci 2013; 70: 1055-66.

102. Hoeben A, Landuyt B, Highley MS, Wildiers H, Van Oosterom AT, De Bruijn EA. Vascular endothelial growth factor and angiogenesis. Pharmacol Rev. 2004; 56:549-80.

103. Sovak MA, Arsura M, Zanieski G, Kavanagh KT, Sonenshein GE. The inhibitory effects of transforming growth factor betal on breast cancer cell proliferation are mediated through regulation of aberrant nuclear factorkappaB/Rel expression. Cell Growth Differ. 1999; 10:53744.
104. Shih T, Lindley C. Bevacizumab: an angiogenesis inhibitor for the treatment of solid malignancies. Clin Ther. 2006; 28:1779-802.

105. Coultas L, Chawengsaksophak K, Rossant J. Endothelial cells and VEGF in vascular development. Nature. 2005; 438:937-45.

106. Olsson AK, Dimberg A, Kreuger J, Claesson-Welsh L. VEGF receptor signalling - in control of vascular function. Nat Rev Mol Cell Biol. 2006; 7:359-71.

107. Maruotti N, Corrado A, Neve A, Cantatore FP. Systemic effects of Wnt signaling. J Cell Physiol. 2013; 228:142832.

108. Chen TS, Lai RC, Lee MM, Choo AB, Lee CN, Lim SK. Mesenchymal stem cell secretes microparticles enriched in pre-microRNAs. Nucleic Acids Res. 2010; 38:215-24.

109. Yoo JK, Kim J, Choi SJ, Noh HM, Kwon YD, Yoo H, Yi HS, Chung HM, Kim JK. Discovery and characterization of novel microRNAs during endothelial differentiation of human embryonic stem cells. Stem Cells Dev. 2012; 21:2049-57.

110. Ohyashiki JH, Umezu T, Ohyashiki K. Exosomes promote bone marrow angiogenesis in hematologic neoplasia: the role of hypoxia. Curr Opin Hematol. 2016; 23:268-73.

111. Sahoo S, Klychko E, Thorne T, Misener S, Schultz KM, Millay M, Ito A, Liu T, Kamide C, Agrawal H, Perlman H, Qin G, Kishore R, Losordo DW. Exosomes from human CD34(+) stem cells mediate their proangiogenic paracrine activity. Circ Res. 2011; 109:724-28.

112. Hu GW, Li Q, Niu X, Hu B, Liu J, Zhou SM, Guo SC, Lang HL, Zhang CQ, Wang Y, Deng ZF. Exosomes secreted by human-induced pluripotent stem cell-derived mesenchymal stem cells attenuate limb ischemia by promoting angiogenesis in mice. Stem Cell Res Ther. 2015; 6:10.

113. Qi X, Zhang J, Yuan H, Xu Z, Li Q, Niu X, Hu B, Wang Y, Li X. Exosomes Secreted by Human-Induced Pluripotent Stem Cell-Derived Mesenchymal Stem Cells Repair Critical-Sized Bone Defects through Enhanced Angiogenesis and Osteogenesis in Osteoporotic Rats. Int J Biol Sci. 2016; 12:836-49.

114. Nakamura Y, Miyaki S, Ishitobi H, Matsuyama S, Nakasa T, Kamei N, Akimoto T, Higashi Y, Ochi M. Mesenchymalstem-cell-derived exosomes accelerate skeletal muscle regeneration. FEBS Lett. 2015; 589:1257-65.

115. Sun Q, Zhang Y, Yang G, Chen X, Zhang Y, Cao G, Wang J, Sun Y, Zhang P, Fan M, Shao N, Yang X. Transforming growth factor-beta-regulated miR-24 promotes skeletal muscle differentiation. Nucleic Acids Res. 2008; 36:269099.

116. Naguibneva I, Ameyar-Zazoua M, Polesskaya A, Ait-SiAli S, Groisman R, Souidi M, Cuvellier S, Harel-Bellan A. The microRNA miR-181 targets the homeobox protein Hox-A11 during mammalian myoblast differentiation. Nat Cell Biol. 2006; 8:278-84. 
117. Furuta T, Miyaki S, Ishitobi H, Ogura T, Kato Y, Kamei N, Miyado K, Higashi Y, Ochi M. Mesenchymal Stem CellDerived Exosomes Promote Fracture Healing in a Mouse Model. Stem Cells Transl Med. 2016; 5:1620-30.

118. Zhang J, Liu X, Li H, Chen C, Hu B, Niu X, Li Q, Zhao B, Xie Z, Wang Y. Exosomes/tricalcium phosphate combination scaffolds can enhance bone regeneration by activating the PI3K/Akt signaling pathway. Stem Cell Res Ther. 2016; 7:136.

119. Qin Y, Wang L, Gao Z, Chen G, Zhang C. Bone marrow stromal/stem cell-derived extracellular vesicles regulate osteoblast activity and differentiation in vitro and promote bone regeneration in vivo. Sci Rep. 2016; 6:21961.

120. Hao ZC, Lu J, Wang SZ, Wu H, Zhang YT, Xu SG. Stem cell- derived exosomes: A promising strategy for fracture healing. Cell prolif. 2017; 50.

121. Mardones R, Jofré CM, Minguell JJ. Cell therapy and tissue engineering approach for cartilage repair and/or regeneration. Int J Stem Cells. 2015; 8:48-53.

122. Carulli C, Innocenti M, Brandi ML. Bone vascularization in normal and disease conditions. Front Endocrinol (Lausanne). 2013; 4:106.

123. Carulli C, Luzi E, Macera A, Innocenti M. MicroRNA in Regenerative Medicine. Elsevier; 2014. p. 40.

124. Zhang J, Guan J, Niu X, Hu G, Guo S, Li Q, Xie Z, Zhang C, Wang Y. Exosomes released from human induced pluripotent stem cells-derived MSCs facilitate cutaneous wound healing by promoting collagen synthesis and angiogenesis. J Transl Med. 2015; 13:49.

125. Khan M, Nickoloff E, Abramova T, Johnson J, Verma SK, Krishnamurthy P, Mackie AR, Vaughan E, Garikipati VN, Benedict C, Ramirez V, Lambers E, Ito A, et al. Embryonic stem cell-derived exosomes promote endogenous repair mechanisms and enhance cardiac function following myocardial infarction. Circ Res. 2015; 117:52-64.

126. Kim SH, Lechman ER, Bianco N, Menon R, Keravala A, Nash J, Mi Z, Watkins SC, Gambotto A, Robbins PD. Exosomes derived from IL-10-treated dendritic cells can suppress inflammation and collagen-induced arthritis. J Immunol. 2005; 174:6440-48.

127. Fleury A, Martinez MC, Le Lay S. Extracellular vesicles as therapeutic tools in cardiovascular diseases. Front Immunol. 2014; 5:370.

128. Qin Y, Sun R, Wu C, Wang L, Zhang C. Exosome: A Novel Approach to Stimulate Bone Regeneration through Regulation of Osteogenesis and Angiogenesis. Int J Mol Sci. 2016; 17:E712.

129. Harshyne LA, Nasca BJ, Kenyon LC, Andrews DW, Hooper DC. Serum exosomes and cytokines promote a T-helper cell type 2 environment in the peripheral blood of glioblastoma patients. Neuro Oncol. 2016; 18:206-15.

130. Huang J, Zhao L, Xing L, Chen D. MicroRNA-204 regulates
Runx2 protein expression and mesenchymal progenitor cell differentiation. Stem Cells. 2010; 28:357-64.

131. Hassan MQ, Maeda Y, Taipaleenmaki H, Zhang W, Jafferji M, Gordon JA, Li Z, Croce CM, van Wijnen AJ, Stein JL, Stein GS, Lian JB. miR-218 directs a Wnt signaling circuit to promote differentiation of osteoblasts and osteomimicry of metastatic cancer cells. J Biol Chem. 2012; 287:4208492.

132. Li Z, Hassan MQ, Volinia S, van Wijnen AJ, Stein JL, Croce CM, Lian JB, Stein GS. A microRNA signature for a BMP2-induced osteoblast lineage commitment program. Proc Natl Acad Sci USA. 2008; 105:13906-11.

133. Kim YJ, Bae SW, Yu SS, Bae YC, Jung JS. miR-196a regulates proliferation and osteogenic differentiation in mesenchymal stem cells derived from human adipose tissue. J Bone Miner Res. 2009; 24:816-25.

134. Raposo G, Stoorvogel W. Extracellular vesicles: exosomes, microvesicles, and friends. J Cell Biol. 2013; 200:373-83. 